\title{
A PROCEDURE FOR THE ANALYSIS AND DESIGN OF DUCTILE REINFORCED CONCRETE FRAME BUILDINGS OF MODERATE HEIGHT
}

\author{
R. L. Williams*
}

\begin{abstract}
A procedure is presented in step by step form for designing and detailing a reinforced concrete frame building to the requirements of DZ4203 (Draft New Zealand loading code). Consideration is given for adequate ductility by means of a capacity design approach to all members to obtain a large number of plastic hinges which are detailed to dissipate energy without brittle failure. Further ductile detailing is given for all other locations where accidental hinges could occur and to limit excessive deflections that may result from deterioraticn of beam column joints.
\end{abstract}

\section{OBJECT:}

The object of the procedure is to design a structure which will perform in a predictable and ductile manner when lateral earthquake loads exceed the nominal code recuirements, with a large number of plastic hinges being generated in order to provide adequate energy absorption. Such plastic hinges will, in general, form in the beams and thus enables the building to be subsequently repaired. The Draft New Zealand Standard Code of Practice D.Z.4203 "General Structural Design and Design Loading" 1973. Draft N.Z. Code of Practice applies.

\section{NOTATION:}

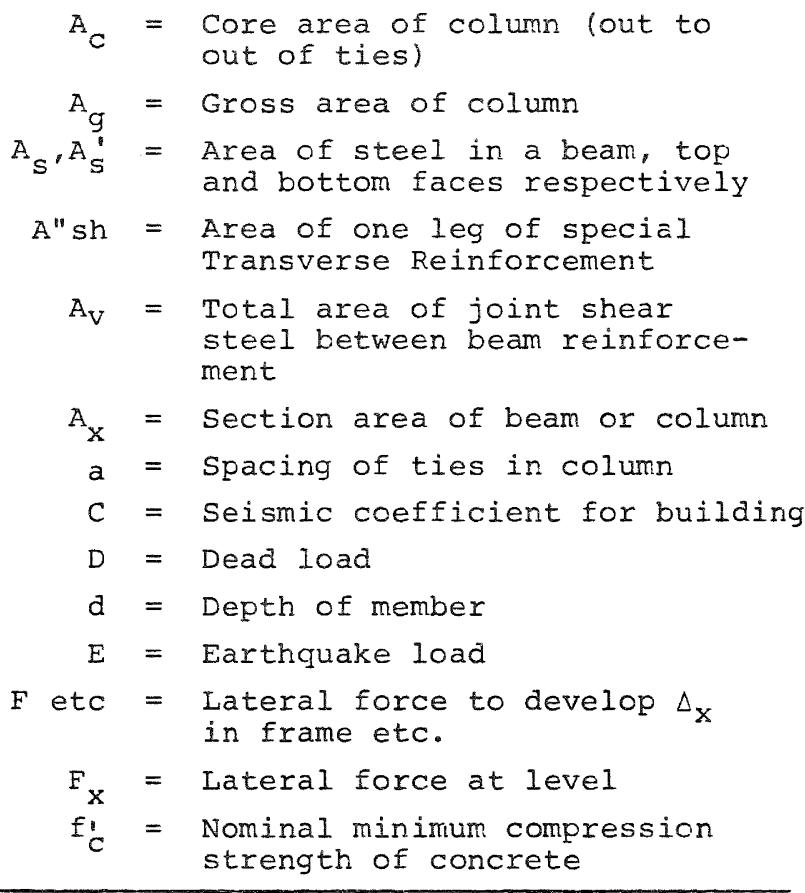

* District Structural Engineer, Ministry of Works and Development, Hamilton, New Zealand.

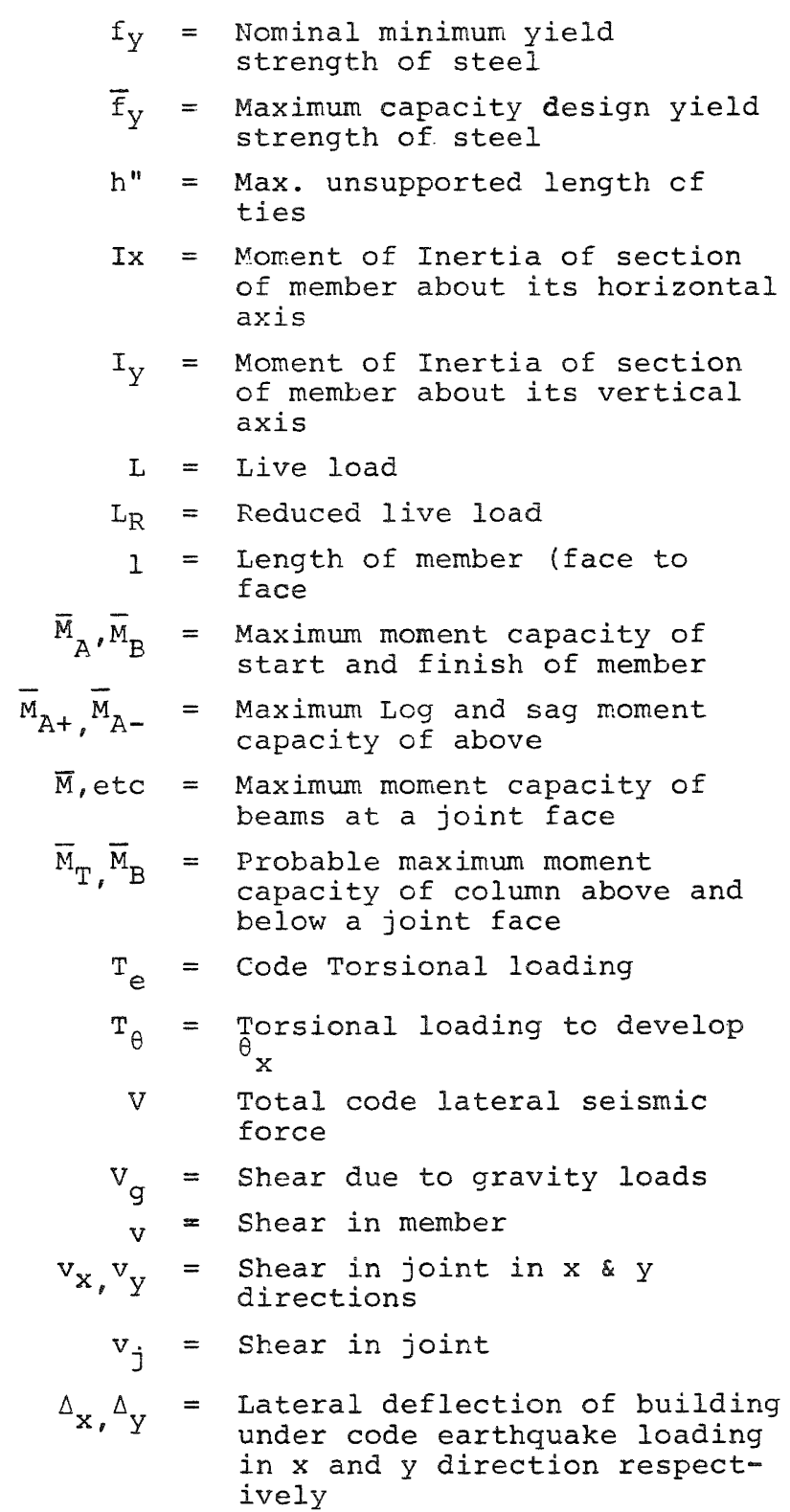




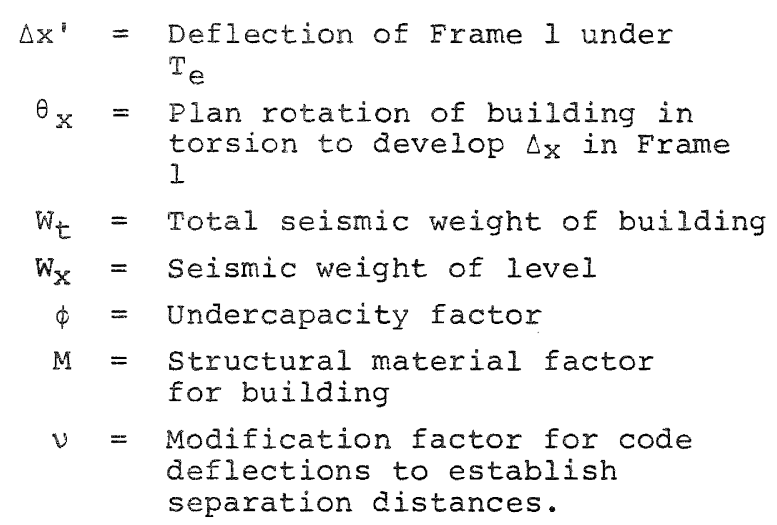

Summary of Steps

$1-10 \quad \begin{aligned} & \text { Methods of elastic analysis of } \\ & \text { the frame } \\ & \text { Design of beam flexural steel } \\ & \text { at column faces } \\ & \text { Design of beam column joint } \\ & \text { steel to cover shear development } \\ & \text { from beam capacities }\end{aligned}$

\section{Philosophy of Design}

The initial design is by elastic methods as the direct application of plastic design may lead to undesirably large rotations of a few members at low lateral loads. On small earthquakes it is desirable to keep the whole structure within the elastic range and limit damage. The design of joint steel is considered to be most important as even cracking in this area can lead to high joint rotations and thus excessive interstorey deflections with consequent non structural damage. The columns are designed to provide excess capacity over the beams at the joints so that plastic hinges in the columns are avoided. Nevertheless dynamic investigations suggest that even with these precautions column hinges can still occur. Other effects such as non structural partitions stiffening parts of the structure can induce column failures elsewhere.

The consequences of column failure are so serious that every effort must be made to ensure that the best possible performance of them is obtained. Finally the effects of lifting and rocking of foundations must be considered as such movernent could invalidate the assumed plastic hinge locations and reduce the damping and lateral resistance of the building.

\section{PROCEDURE:}

1. Select grids, storey heights and trial member sizes. Experience and knowledge of the procedure will help at this stage. Even bay sizes, 2 way floor systems and short to moderate spans, producing low gravity induced moments are found to ease design problems. Use of beam stubs and the use of deeper than average beams also ease the acute detailing problem at beam - column joints. Generous column sizes are found to be necessary in order to detail strong enough columns to resist the formation of column hinges and the development of high joint shears, particularly under biaxial bending.

2. Establish the vertical gravity loads and derive the seismic load, Wt. usually $1.12 \mathrm{D}$ or $(\mathrm{D}+L / 3)$ and thus obtain the lateral code loads for the building assuming the max. zone coefficient (i.e. short building period).

Total Lateral Force $V=C$ I S M R (refer draft code) (I)

$\mathrm{V}$ is then distributed by the formula

$$
F_{X}=\frac{V \cdot W_{X} h_{X}}{\sum W_{X} h_{X}} \quad \begin{gathered}
\text { (refer araft code } \\
\text { again) }
\end{gathered}
$$

3. A preliminary analysis by the Muto method (5) is recommended at this stage to check preliminary membex sizes, max. steel contents in beam columns and joints. This analysis will also prove useful later as a check on computer runs.

4. Prepare the full computer analysis (M.W. D. uses ICES STRUDL), (6) keeping in mind the following points:

(a) Use end joint size function for beams and columns to give infinite stiffness within the joint.

(b) The function $A_{y}$ (shear area) is usually ignored because shear deformation is taken as zero for normally proportioned beams.

(c) The section area $\left(A_{X}\right)$ is usually increased to a large number for beam areas to simulate diaphragm action in a plane frame analysis and space frame analysis. (d) In space frame analysis Iy (lateral stiffness of beams) may be increased to a large number to simulate diaphragm action. or pin ended diagonal struts may be added (see Fig. 1). In plane frame analysis the frames may be linked by pin ended struts (see Fig, 2).

(e) For columns, $A_{X}$ (section area) is normally left at its real value with the exception of tall buildings where it is advisable to increase it by 2 or $3 \times$ for the gravity parts of the analysis as the apparent differential shortening between lightly and heavily loaded columns is reduced by factors such as creep and shortening during construction.

5. Apply the full lateral loading with allowance for torsional loads (the new draft code has increased torsional loads).

$$
\begin{aligned}
& \text { The tortion is based on the formula } \\
& \text { ed }=1.7 \text { es }-\frac{\theta s}{b}+0.1 b
\end{aligned}
$$

or ed $=$ es $-0.1 \mathrm{~b}$ whichever is greater, where es is the static eccentricity

With space frames torsion can be applied directly to the computer model. With plane frame analysis apply the lateral load to the frame without allowance for torsion 
(fig. 4) producing a deflection of $\Delta x$. Then from the forces in the link member the forces resisted by each frame under the constant deflection $\Delta x$ can be deduced. Call these forces resisted by each frame $F_{1}, F_{2}, F_{3}$ etc. Similarly for direction $\mathrm{Y}$ calls $\mathrm{F}_{5}, \mathrm{~F}_{6}, \mathrm{~F}_{7}$ etc. under constant deflection consider the nominal torsional state when frame 1 is under a deflection (see Fig. 5). The total moment of resistance Te generated by this nominal state.

$$
\begin{aligned}
T_{\theta} & =F_{1} x_{1}+F_{2} \cdot \frac{x_{2}{ }^{2}}{x_{1}}+F_{3} \cdot \frac{x_{3}^{2}}{x_{1}}+F_{4} \cdot \frac{x_{4}{ }^{2}}{x_{1}} \\
& +F_{S} \frac{\Delta x}{\Delta y} \cdot \frac{y 5^{2}}{x_{1}}+F_{6} \cdot \frac{\Delta x}{\Delta y} \cdot \frac{y_{6}{ }^{2}}{x_{1}}+F_{7} \cdot \frac{\Delta x}{\Delta y} \cdot \frac{y_{7}^{2}}{x_{1}} \\
& =\frac{1}{x_{1}}\left(\sum_{x \rightarrow \infty} F_{n} x_{n}{ }^{2}+\frac{\Delta x}{\Delta y} \sum F_{n} y_{n}^{2}\right)
\end{aligned}
$$

However if $\mathrm{T}_{e}$ is the design torsion

then the deflection produced by $\mathrm{T}_{e}$ in Frame 1 is $\Delta x^{\prime}$

$$
\text { such that } \Delta x^{\prime}=\Delta x \frac{T_{e}}{T_{\theta}}
$$

therefore $F$ the force in Frame 1

induced by torsion $=\frac{\Delta x^{\prime}}{\Delta x} \times F_{1}=\frac{T_{e}}{T_{\theta}} \times F$

and in the general case

$F_{n}=\frac{T_{e}}{T_{\theta}} \cdot \frac{x_{n}}{x_{1}}$ or $F_{n}=\frac{T_{e}}{T_{\theta}} \cdot \frac{\Delta x}{\Delta y} \cdot \frac{Y_{n}}{Y_{s}}$

In the particular case of similar bays both ways and square columns (see fig 3) an approximation to the fractional increase in lateral force in the particular grid being considered is

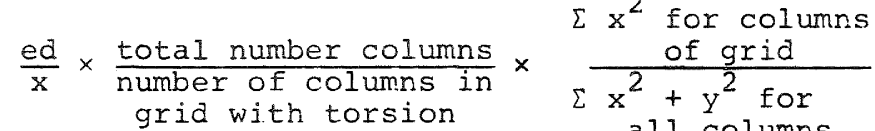

6. Analyse lateral load case with torsion.

7. Check that the maximum interstorey drift under lateral load is not excessive for the proposed detailing of non structural members and in any case the modified interstorey drift shall not exceed.01 of the storey height $(36 \mathrm{~mm}$ for a $3.6 \mathrm{~m}$ storey height). Note that this is the deflection under code loading increased by the factor (refer N.Z. Code) of about 2.5. In addition the code requires that full allowance for detailing of interstorey drift be made in non structural items such as rigid portions and infills, precast, glazing etc. when modified interstorey drift exceeds .0006 times storey height $(2.2 \mathrm{~mm}$ for a $3.6 \mathrm{~m}$ storey height).

8. From deflection of building establish deflection that would correspond to the vertical seismic loads, Wx etc, applied horizontally ard multiplied by a factor varying from zero at the bottom to unity at the top. This deflection may be used to establish the building period. If the building period varies from that assumed re-runcomputer analysis with revised lateral loading coefficient.

\section{Analyse gravity cases}

(i)

$$
1.4 \mathrm{D}+1.7 \mathrm{I}_{\mathrm{R}}
$$$$
D+1.3 \mathrm{~L}_{\mathrm{R}}
$$

The reduced live load, $I_{R}$, is applied to each beam based on the reduction for the area that the beam supports. No further reductions are applied until column detailing is considered.

10. Add lateral load moments to gravity moments to obtain load cases

(i) $\mathrm{D}+1.3 \mathrm{~L}_{\mathrm{R}}+\mathrm{E}$ and (ii) .9D $+\mathrm{E}$ for the beams although gravity moments may be relaxed $30 \%$ at continuous supports before addition and some of the slab steel may be used to assist in taking the negative gravity moment (2).

As the best performance of plastic hinges in reinforced concrete members under cyclic loading is achieved with equal top and bottom steel, relaxation of the gravity moments as in Fig. 6 , also refer (2), is most desirable. Fig 6 (a) illustrates that the bottom steel is usually the damping medium in the structure and that tensile and compressive yielding of it is preferable to buckling.

An alternative method of equalizing top and bottor steel is to use a central post tensioning strand draped at centre span to remove most of the gravity loads.

11. Design beam flexural steel at column faces. The factor that usually governs beam sizes is the beam column joint shear steel. This can best be accommodated by increasing the beam depth close to the limit for ductility (SEAOC (4) says $b / d>.3$ ) and utilising its maximum lever arm in order to keep beam flexural steel to a minimum.

Beam stubs projecting out from exterior beam column joints prove to be most useful by giving adequate joint stiffness and reducing seismic damage.

Eccentric beam-column joints develop considerable additional internal joint shear and should be avoided wherever possible.

Flexural steel is designed by normal U.S.D. methods with minimum, specified yield strength and code factors.

The limits of steel percentages when using 27.5 MPa concrete and $275 \mathrm{MPa}$ min yield stress steel are:

$$
\begin{aligned}
& \text { Minimum for beam }=\frac{200}{f y}=.5 \% \\
& \text { Maximum in the code is } .46 \frac{f^{\prime} c}{f y} \cdot \frac{P^{\prime}}{P} \text { and if } \\
& \text { top steel }=\frac{4}{3} \times \text { bottom steel, } \max =3.45 \%
\end{aligned}
$$

The recommended percentages for satisfactory capacity design are $0.6 \%$ to $1.2 \%$ for top steel, using the higher percentage for lower storey beams in multistorey construction.

At this stage design philosophy changes from elastic analysis with Ultimate strength 
Design at the normal min. yield strength of reinforcing steel to capacity design considering the yield capacity of members including such effects as the maximum yield strength of steel fy plus the capacity from adjacent slab steel, depending on details, plus tension in the concrete etc. With our normal fy $=275 \mathrm{MPa}$ steel NZS $3423 \mathrm{P} .1972$ we can make an allowance of $10 \%$ for increased yield strength, $10 \%$ for strain hardening and say 5\% for other effects giving a yield capacity based on say $\tilde{F}_{Y}=275 \times 1.25=$ $344 \mathrm{MPa}$.

Bond stresses in the beam flexural steel as it passes through the joint area are extremely high, well above normal limits, and every effort must be made to minimise these if slippage and loss of stiffness of the joint is to be avoided. It is suggested that a large number of smaller bars (D28 or less) be used and that larger bars or high yield strength bars be avoided. More research is needed in this area.

\section{Check joint shear and detail}

$$
v_{j}=A s \bar{f}_{Y}+A \dot{S} \bar{f}_{Y}-H \quad \text { (uniaxial) }
$$

The nominal shear stress in the joint should be checked. It is suggested that this stress should not approach $1.66 \sqrt{\mathrm{f}_{\mathrm{C}}} \mathrm{MPa}$.

In outside column beam joints without cantilevers

$$
v_{j}=A s \bar{f}_{Y}-H
$$

$H$, the column shear may be taken from the elastic analysis.

The shear is resisted by the shear steel cut by the corner to corner crack across the joint (see Fig. 7) and where biaxial bending is possible the crack may occur across the diagonal corners of the joint (see Fig. 9a) and flexural steel in both directions may be in yield at the same time increasing the shear.

No allowance is made for the shear carried by the concrete. This may not be entirely correct but on the other hand not all the ties can be expected to be fully effective so we could say these effects even out.

Some codes allow for a $50 \%$ reduction in Av where the joint is adequately confined by beams or beam stubs on all sides. The effect on this confinement however is disputed for biaxial bending (Ref 9) because large flexural cracks will occur adjacent to the beam-column joint. Further research is required to ascertain the effect of the confinement and in the meantime it is recommended that this reduction factor not be used.

The vertical component of the shear also has to be resisted. This is usually resisted by column axial load and column steel and it is suggested that the latter is most effective when evenly distributed around the perimeter of the column.

When detailing beam column joints it will be found to be virtually impossible to bend off beam flexural steel within the joint and as a result beam stubs are strongly recommended.

Development of anchorage of flexural steel can be taken as commencing $2 / 3$ of the way through the column (see Fig. 8 (a)). Note that the thrust at the bend produces a desirable compression strut. An alternative method that allows easier steel placement is the use of anchor plates (Ref. 10, 11, 12) (see Fig. 8 (b)). Note that bent down steel develops a desirable compression strut and that when a plate is used ties mäy be desirable to take the vertical component.

With two way frames concurrent beam hingeing can occurin both planes as a result of a skew earthquake with lateral displacements exceeding the yield displacement in each direction. The joint shear is increased in these cases e.g. square columns with equal beams intersecting from both directions.

If square ties are used the effective area is reduced to $\frac{1}{2} x$ original while the crack still $\sqrt{2}$ crosses the same number of ties with a result that the area of ties required is increased to twice the uniaxial case. (see Fig. 9a, 9b). In more complex tie arrangements the actual potential crack has to be drawn and the actual steel area crossing the crack must be analysed. (see Appendix). Special transverse reinforcement does not always govern the joint shear steel but may well dictate the geometry and type of ties used.

13. Detail Cut off Points for flexural steel in beams. To do this first draw the envelope of the design moments and in cases where there has been a significant overdesign of steel the following adjustments may be necessary. Indicate the actual steel supplied through the joint on this diagram by subtracting them from the envelope and call these the new base lines. By adding the wedges so formed to the first envelope, a new envelope is formed (see Fig. 10). Establish cut offs in the normal manner. This operation improves on the chances of plastic hinges forming near the column - beam joints.

14. Design shear steel from the gravity shear plus the maximum shears that can be developed by the plastic hinges i.e. $V_{g} \pm\left(\bar{M}_{A}+\bar{M}_{B}\right) / 1$ (see fig. 11) where $\bar{M}_{A}, \bar{M}_{B}$ are the capacities of the yield of the steel and $\phi=1$ at the column and 1 the span from $\bar{M}_{A}$ to $\bar{M}_{B}$, usually the column face separation. Check that the gross shear stress on any member under cyclic loading does not exceed $0.5 \sqrt{\hat{f}} \mathrm{C}$ ( $f C$ in MPa).

No allowance for the shear capacity of the concrete itself can be used when designing shear steel within $2 d$ of the column faceeas plastic hinges normally form in this location. It should also be noted that in frames with large gravity moments the position of one hinge could occur away from the face of the column and in such case the $2 d$ requirement should be extended (see Fig. 12).

In detailing beam steel it is desirable to ensure that no flexural steel is terminated within $2 d$ plus anchorage of the 
column face and that in the area $2 \mathrm{~d}$ from the column that special attention be given to preventing the flexural steel from buckling under alternating cycles of yield compression and yield tension. Arrange for shear steel to confine all flexural steel as in Fig. 13. Spacing of ties in area of potential hinges should not exceed $100 \mathrm{~mm}$ if buckling of bars in compression is to be avoided. Ties should be spaced starting hard against column steel.

15. Design column flexural reinforcement

Axial forces result from (a) dead and live load (b) beam hingeing under lateral earthquake loading.

The beam hingeing which occurs under the lateral load develops the shears $\left(\bar{M}_{A}+\bar{M}_{B}\right) / I$ in each of the beams around the column (as in section 13). For the interior columns two of these will be upwards and two downwards (see Fig. 14) and little net axial force will develop, but on exterior and particularly corner columns substantial uplift or downthrust can be generated.

These beam shears are accumulated for all joints above the point under consideration, however, with special investigation it may be possible to base this on full shears for the 6 levels above and reduced shears from levels above that as on very tall buildings where simultaneous hingeing of the beams up to the full height of the buildings appears to be unlikely.

The axial force load cases are:

$$
\begin{aligned}
& 1.4 \mathrm{D}+1.7 \mathrm{~L}_{\mathrm{R}} \\
& \mathrm{D}+1.3 \mathrm{~L}_{\mathrm{R}} \pm \mathrm{E}
\end{aligned}
$$

(iii) .9D $\pm \mathrm{E}$

Where $L_{R}$ is the reduced live load for the area supported by the column and $E$ is $t$ $\sum\left(\bar{M}_{A}+\bar{M}_{B}\right) / 1$ the moments generated at the joint are derived from the capacity of the beams around the joint. For capacity design, but with points of inflection at mid storey height $M_{T}+M_{B}>\bar{M}_{1}+\bar{M}_{2}+\bar{M}_{3}+$ $\bar{M}_{4}$ (see Fig. 15) $\bar{M}_{1}, \bar{M}_{2}, \bar{M}_{3}, \bar{M}_{4}$ are added vectorally in biaxial cases. An exception to this formula is that column hinges may be accepted in cases where the whole column section is in tension (i.e. extreme uplift in end or corner bays).

However there is no guarantee that the point of contraflexure will occur near the mid height of the column and therefore it is suggested that

$$
M_{T}\left(\text { or } M_{B}\right) \geqslant .8 \sum\left(\bar{M}_{1}+\bar{M}_{2}+\bar{M}_{3}+\bar{M}_{4}\right)
$$

Calculate the column interaction diagram. This can be done manually in which case trial neutral axes can be taken and the ultimate moment and axial capacities plotted for them. (see Fig. 15).

The trial neutral axes are kept parallel to each other and usually perpendicular to the critical biaxial moment conditions that are to be considered.

Alternatively the I.C.E.S. Secdes programme may be used to produce an interaction diagram across diagonal of the section (neutral axes considered perpendic- ular to this diagonal). Alternatively an approximation can be obtained by the Weber method (7) by which the interaction values can be interpolated given the uniaxial interaction values and the diagonal value. Breslar's method (8)

allows an approximation given the uniaxial interaction values and the ultimate axial capacity.

Plot and select a reinforcement arrangement.

Arrangements with bundled bars may be effective in resisting biaxial moments but adequate lap lengths are difficult to achieve.

16. Design column shear steel reinforcement.

$$
\mathrm{v}=\frac{\overline{\mathrm{M}}_{\mathrm{A}}+\overline{\mathrm{M}}_{\mathrm{B}}}{1} \text { where } \overline{\mathrm{M}}_{\mathrm{A}^{\prime}}, \overline{\mathrm{M}}_{\mathrm{B}} \text { are the maximum }
$$

capacity column face moments at the joints and 1 is the face to face distance between beams. The moment capacities are derived from the maximum yield strength of the steel, $\phi=1$ and full cover concrete. (see Fig. 16.)

This gives the maximum moment that can be generated by the column under maximum axial load or at the balance point if this is less than the maximum moment.

With two-way frames biaxial shears should be considered. The steel cut by by $45^{\circ}$ biaxial crack is often sufficient to cover the increased shear.

The shear is to be taken entirely on the reinforcement within the region, max. column dimension from the ends of the columns or column height $/ 6$.

\section{Special Transverse Reinforcement}

The M.O.W. Design of Public Buildings (2) requirements for confining the potential hinge areas in columns are based on the A.C.I. and SEAOC requirements and are as follows.

The basis of the equations appears to be that no significant loss of axial strength can be tolerated when cover concrete spalls off. This may not be completely applicable to seismic columns where axial loads (except in corner columns under biaxial bending) are usually below capacity. However the general effect of the equations are most valuable in providing confining steel.

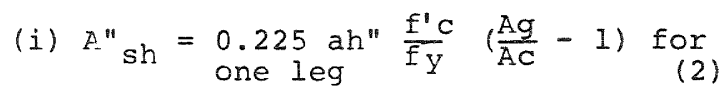

$$
\begin{aligned}
& \text { or (ii) } A^{\prime \prime} \text { sh }=0.06 a h^{\prime \prime} \frac{f^{\prime} c}{f y} \text { for one leg, which- } \\
& \text { ever is gryeater }
\end{aligned}
$$

If columns are designed on the core only i.e. cover concrete ignored, then equation (i) can probably be ignored. The M.O.W. provisions (2) allow some reduction in A" when cross ties are used. $75 \%$ for single and $67 \%$ for double ties.

Items not entirely clear in the codes could be interpreted as follows: 
(i) For Ac use out to out of spirals or ties.

(ii) Cross ties should confine outer but need not hook around vertical bars if adequately tied to them. In practiceit is very difficulty to get a tight fit between ties and thus this type of tie is probably suspect. $25 \mathrm{~mm} \mathrm{~min}$. cover is recommended to all ties.

(iii) Vertical bars can be used as confining ties provided that they themselves are at a spacing of less than $100 \mathrm{~mm}$ and are adequately tied together and the max. spacing of such ties is dependent on the size of vertical bars. (see Fig. 18).

(iv) Max. spacing of cross ties is normally $100 \mathrm{~mm}$, min. dia. is $10 \mathrm{~mm}$ (larger preferred).

(v) Max. $h^{\prime \prime}=350 \mathrm{~mm}$ (for definition see Fig. 17).

Special Transverse Reinforcement is required through the joint plus a distance either side equal to the columns largest dimension or the column height $\div 6$ if greater. A $50 \%$ reduction within the column joint is allowable if the joint is confined by beams on 4 faces. It is well worth considering extending the special transverse reinforcement throughout the column as the increased confinement is usually enough to keep the splices in column bars down to the nominal splice length rather than lap $+20 \%$ and thus away from potential column hinge areas. In no case shall the lap be less than $40 \mathrm{~d}$ or $650 \mathrm{~mm}$.

The equations for special transverse reinforcement infer that confinement is achieved partly by arch action and partly by flexural resistance of the ties. However, from consideration of the small diameter of the ties and their maximum span of $350 \mathrm{~mm}$ it is apparent that the larger vertical steel spanning only $100 \mathrm{~mm}$ is doing most of the confinement. Thus it is suggested that the column might be more effectively confined by locating as many of the vertical bars as possible even if the maximum spacing is exceeded. This has the added advantage, so important in seismic design, that the flexural steel is restricted from buckling when it comes under alternating cycles of yield tension and yield compression.

It is therefore apparent that the provisions for special transverse reinforcement need urgent research and revision.

18. Column Hinges cannot be completely avoided. Hinges form at the base of most columns and often at the underside of roof beams (see Fig. 19).

The column hinge below the roof is usually acceptable because it has only light axial loads on it. The hinges at the column bases are more critical. The columns at column hinges are normally designed for the elastic moments provided this is not less than the design moment of the column at the bottom of the joint above. Shear steel is designed as described earlier. In addition reinforcement may be added to confine a core of concrete within the normal cage. This smaller confined core is to take seismic gravity loads only in the event of failure of the outer concrete and permits the cutting back of any damaged concrete or reinforcement should repair of the plastic hinge area be necessary (see Fig. 20).

Such reinforcement need only be placed over the inmediate hinge area and the longitudinal bars need only be nominal.

Numerical step by step integration methods of earthquake response indicate that other column hinges may also form temporarily unless very great overstrengths for columns are provided. Ductile detailing is therefore required in all cases.

19. Rocking or lifting of foundations due to the tensile forces developed in the exterior columns must be investigated. In general these effects should be avoided as high impact forces can be generated. The basis of analysis from assumed plastic hinges may be invalidated and this could also reduce damping and the lateral resistance of the building. Deeply buried footings, anchor piles or heavy foundation beams may be necessary where these forces get very large.

\section{CONCLUSION}

This paper has presented an analysis procedure for ductile reinforced concrete frame buildings based largely on existing codes and technical papers but presented in an ordered manner which should prove useful to the practical designer of typical buildings.

\section{ACKNOWLEDGEMENTS}

I would like to express my thanks to all the people who helped in the development of this paper and in particular to Mr. A. E. Hansen who checked out much of the procedure through actual designs. The permission of the Commissioner of Works is gratefully acknowledged. The opinions expressed are not necessarily those of the Ministry of Works and Development.

\section{REFERENCES}

(1) DZ 4203" General Structural Design and Design Loadings", 1973 Draft N.Z. Code of Practice.

(2) P.W. 81/10/1: 1970 Code of Practice for "Design of Public Buildings" New Zealand Ministry of Works with amendments, May 1975.

(3) A.C.I. 318-71 Building Code Requirements for Reinforced Concrete.

(4) S.E.A.O.C. "Recommended Lateral Force Requirements" 1971.

(5) "Seismic Analysis of Reinforced Concrete Buildings" - K. Muto 1965.

(6) Ices Strud1 II Computer Programme for "Frame Analysis", Massachusetts Institute of Technology.

(7) "Ultimate Strength Design for Columns with Biaxial Bending", Weber, A.C.I. Journal November 1966.

(8) "Design Criteria for Reinforced Columns Subject to Biaxial Bending", Breslar, A.C.I. Journal November 1960 .

(9) Seismic performance of two full size reinforced concrete beam column joint units. R. W. G. Blakeley, L. M. Megget and M. J. N. Priestley. Bulletin of the New Zealand National Society for Earthquake Engineering, 
Vol. 8 No. I March, 1975.

(10) M.W.D. Central Laboratory test on anchor plates ref. $81 / 30 / 5 / 3$ of 8 December 1969.

(11) "New Zealand Parliament Buildings Beehive", O. A. Glogau, A. J.

Ballintine, R. L. Williams and H. E. Chapman. Proceedings of Fifth

World Conference on Earthquake Engineering, Rome 1973.

(12) "Earthquake resistant design of a 20 storey reinforced concrete building", K. Muto, T. Hisada, T. Tsugawa and S. Beesho. Proceedings of Fifth World Conference on Earthquake Engineering, Rome 1973.

\section{APPENDIX A}

DESIGN OF TYPICAL BEAM COLUMN JOINT

$\begin{array}{ll}\text { Beams } & 900 \times 500 \mathrm{~mm} \\ \text { Column } & 750 \times 750 \mathrm{~mm}\end{array}$

Beam column joint is interior with symmetrical beams in both directions. At joint

$$
\begin{aligned}
& \text { Top steel } 4 \text { - D28 top layer } \\
& 2 \text { - D28 2nd layer }
\end{aligned}
$$

Bottom stee1 2 - D20 2nd layer

$$
4 \text { - B28 bottom layer }
$$

Uniaxial case

$$
\begin{aligned}
& \text { Joint shear } v_{j}=A_{S} f y+A^{\prime} f_{Y}-H \\
& =6 \times 615.7 \times \frac{344}{1000}+(4 \times 616.7+2 \times 314.2) \\
& \times \frac{344}{1000}-530
\end{aligned}
$$

$$
\begin{aligned}
& \text { where } \overrightarrow{\mathrm{f}}_{\mathrm{y}}=344 \mathrm{MPa} \\
& =1271+1063-530=1804 \mathrm{KN}
\end{aligned}
$$

Check gross stress on section

$$
\begin{aligned}
\frac{1804000}{750 \times 750}= & 3.2 \mathrm{MPa} \text { Limit is } 1.66 \sqrt{\mathrm{fc}} \\
& =1.66 \sqrt{30}=9.1 \mathrm{MPa}
\end{aligned}
$$

Try square and hexagonal ties at approx. $80 \mathrm{~mm}$ centres.

i.e. try 8 pairs of ties.

on diagram of joint draw diagonal crack

24 legs are cut in uniaxial direction and 8 at $45^{\circ}$ to it.

$\therefore$ Effective area of steel cut $=24+\sqrt{2}$

$$
=29.65 \text { legs. }
$$

$$
\begin{aligned}
A_{v}=\frac{V_{j}}{\phi f y} & =\frac{1804 \times 1000}{.85 \times 275} \\
& =7717 \mathrm{~mm}^{2}
\end{aligned}
$$

Area of leg $=7717 \times \frac{1}{29.65}=260 \mathrm{~mm}^{2}$

R 20 bars $\left(314.2 \mathrm{~mm}^{2}\right.$ ) adequate for uniaxial case but check biaxial.

\section{Biaxial Case}

Joint shear for equal beams in both directions

$=\sqrt{2 .} \times 1804 \mathrm{KN}$

$=2550 \mathrm{KN}$

Draw diagram of biaxial diagonal crack. Legs of ties cut in biaxial direction

6 at $90^{\circ}$ and 26 at $45^{\circ}$

Legs effective $=6 \frac{+26}{\sqrt{2}}=24.39$ legs

but $A=\frac{V_{j}}{\phi f y}=\frac{2550 \times 1000}{.85 \times 275}=10909 \mathrm{~mm}^{2}$

Area of each leg $=\frac{10909}{24.39}=447 \mathrm{~mm}^{2}$

R 24 bars $\left(452.4 \mathrm{~mm}^{2}\right.$ ) required for biaxial case.

Use 9 pairs of R.24 square and hexagonal ties. 


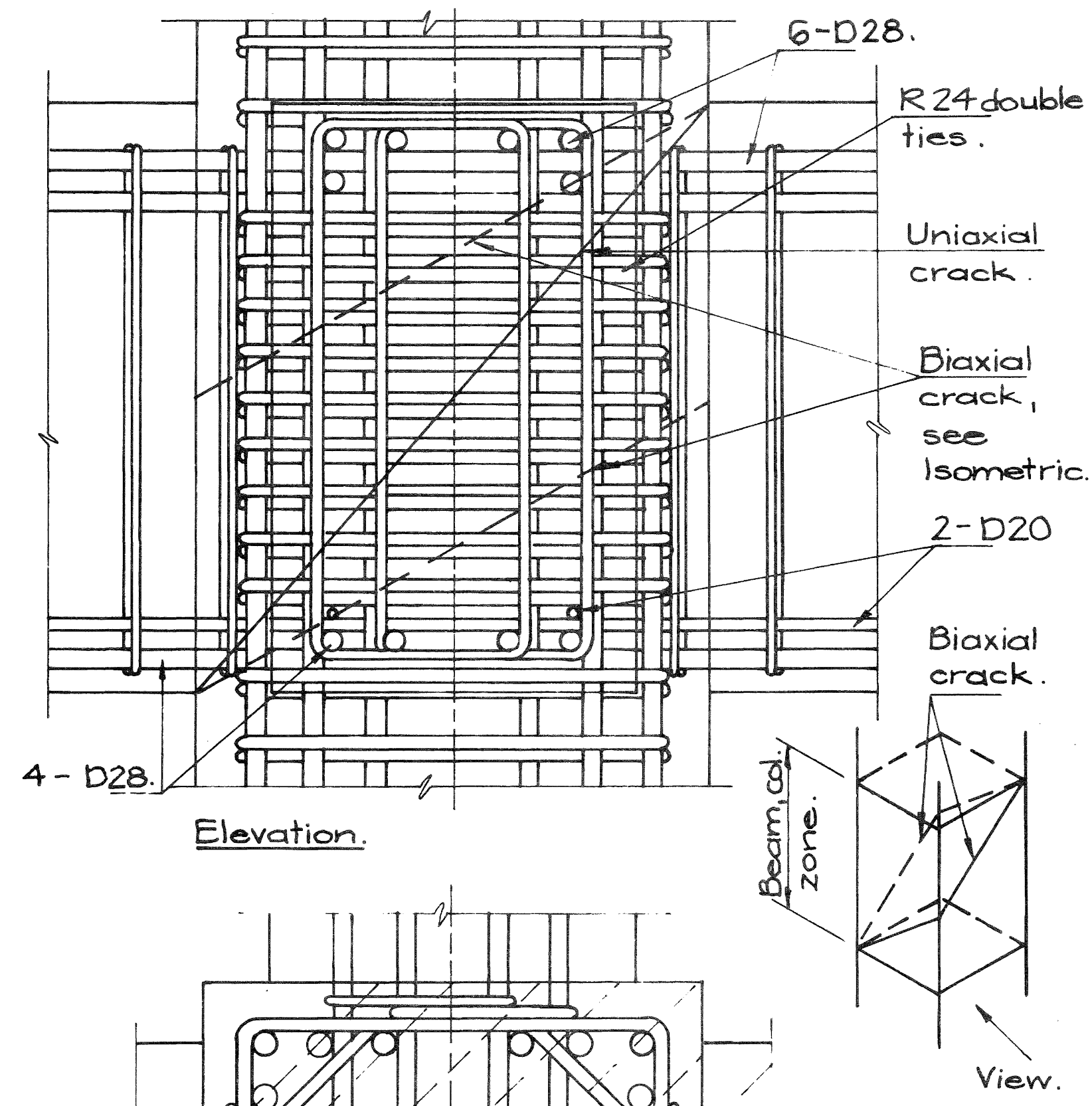

Isometric.

Location

of biaxial

crack as it cuts ties.

plan. 
FLEXURAL STEEL.

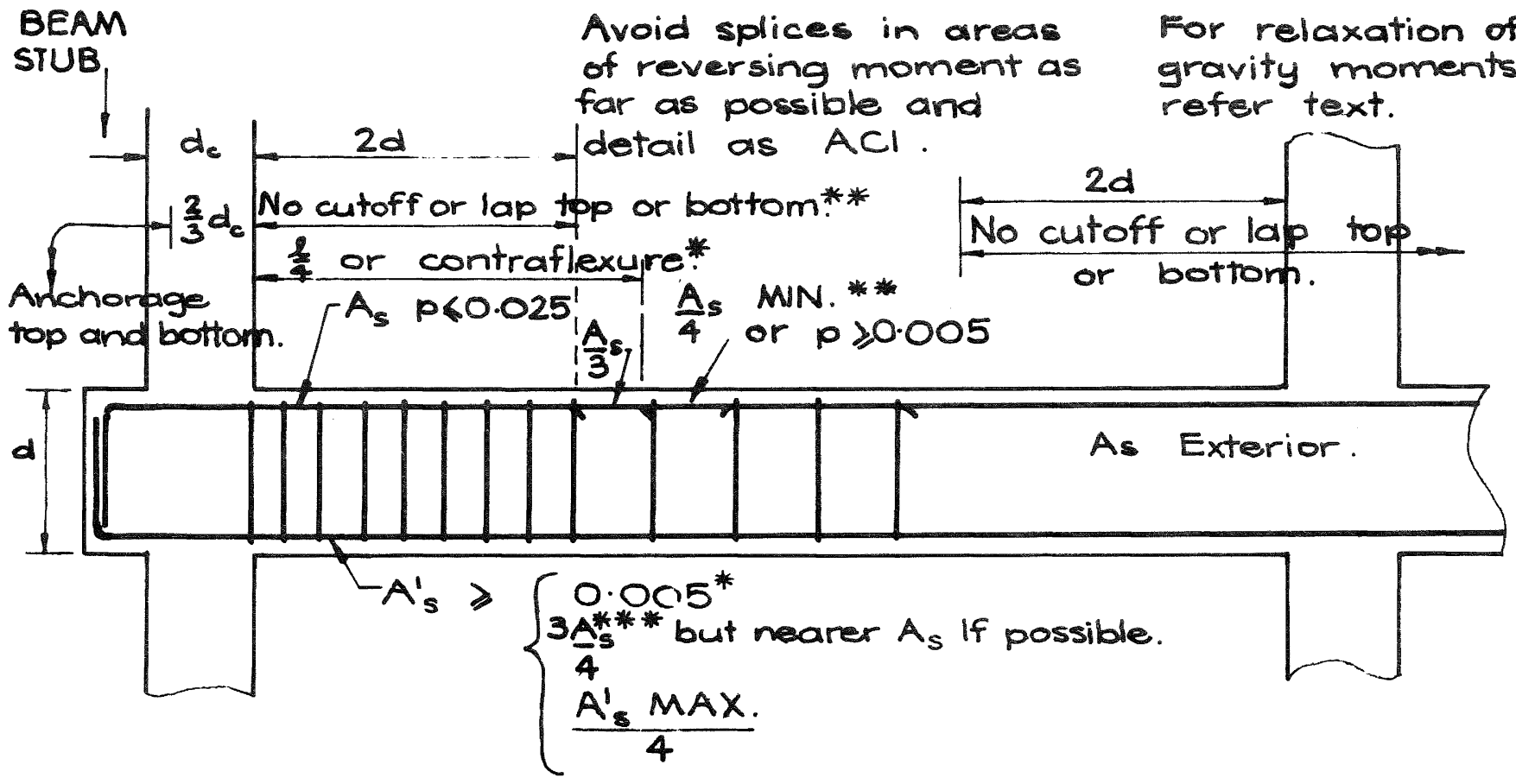

BEAM TIES designod from beam flexural steel capacity, refer text.

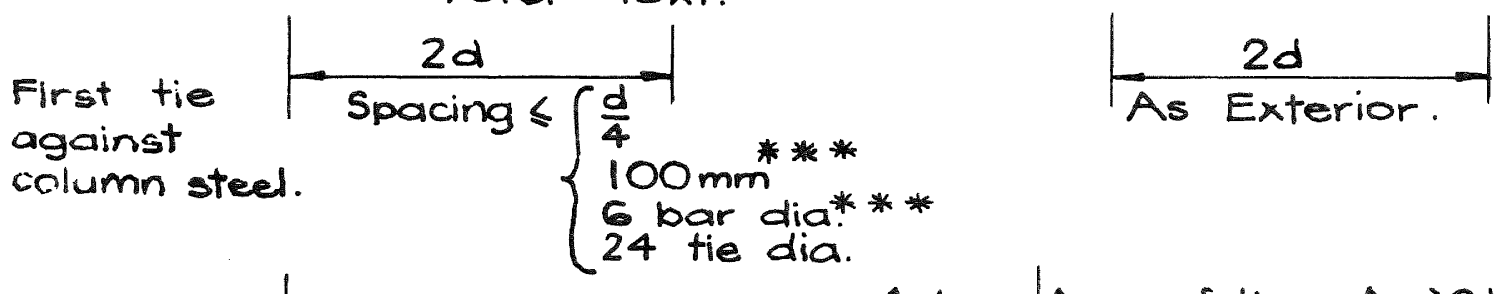

- Spacing $\leqslant \frac{d}{4}$. Area of ties, $A_{v} \geqslant 0.15 A_{s} \frac{s}{d}$.

lateral restraint to

bars as in columns,

e.g. $\rightarrow+150 \mathrm{~mm}^{* *}$ All ties.
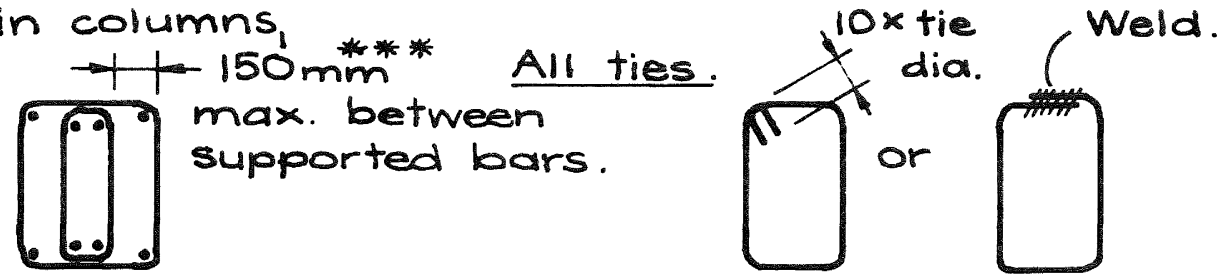

GENERAL.

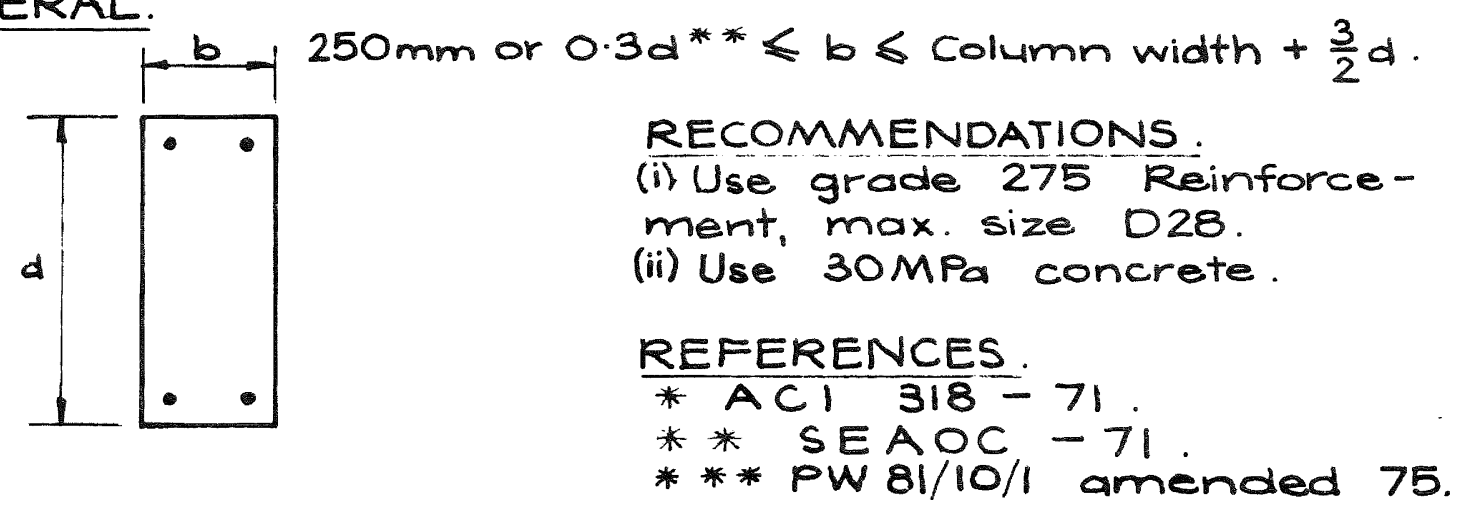


COLUMN TIES designed from flexural steel capacity, refer text.

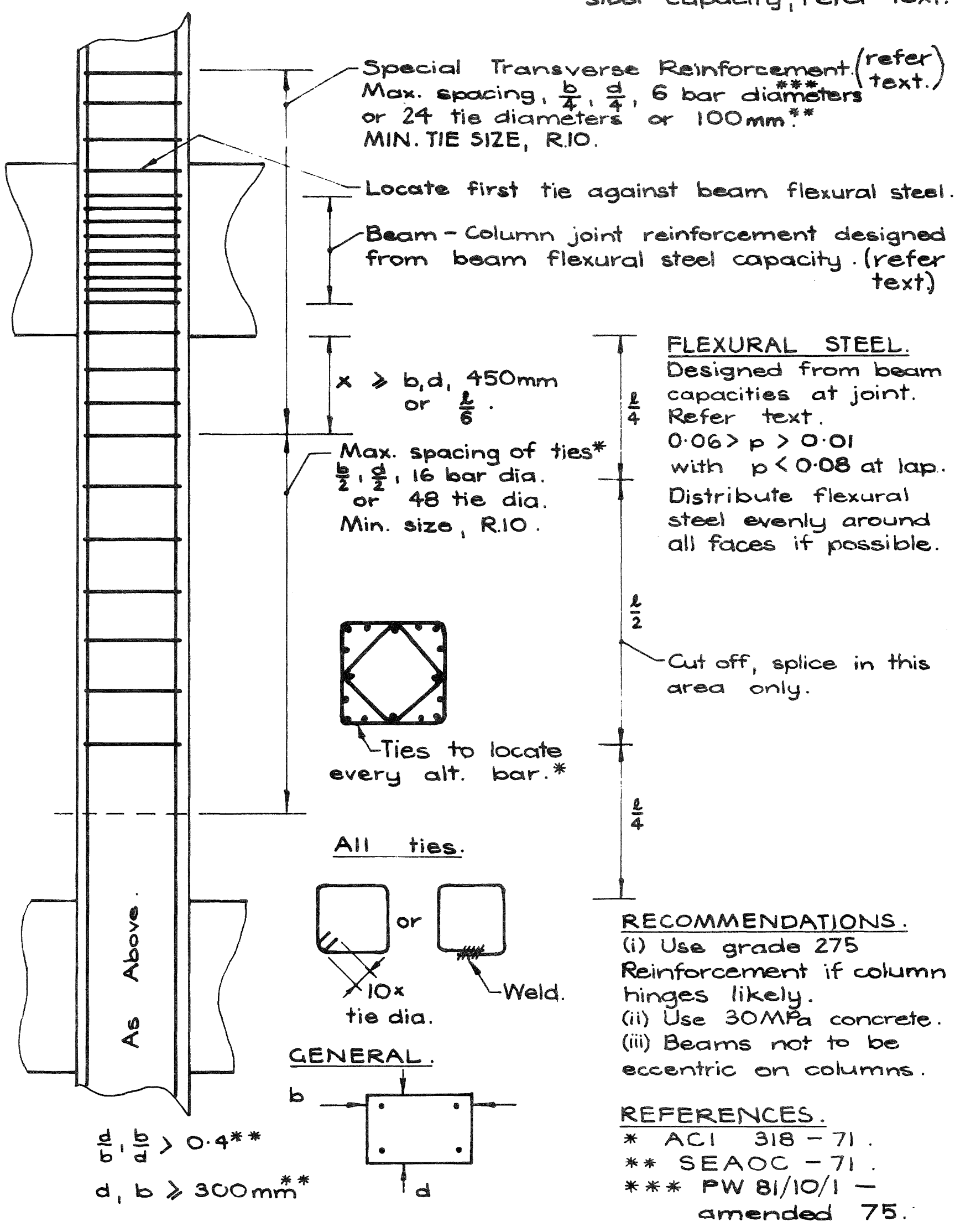




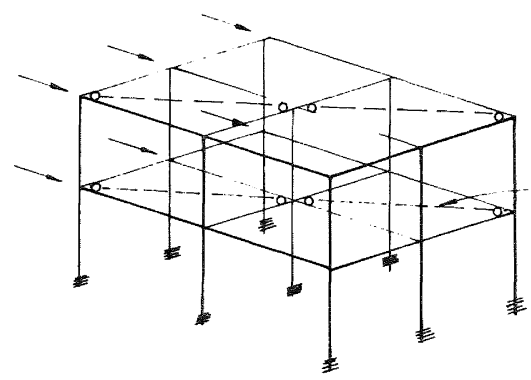

Add diagonal member.

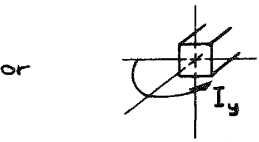

Make $I_{y}$ a large number
for beams.
Increase $A_{\infty}$ for beam to
a large number.
$A_{\infty}$ for columns see text

FIGURE 1: COMPUTER MODEL FOR SPACE FRAME ANALYSIS

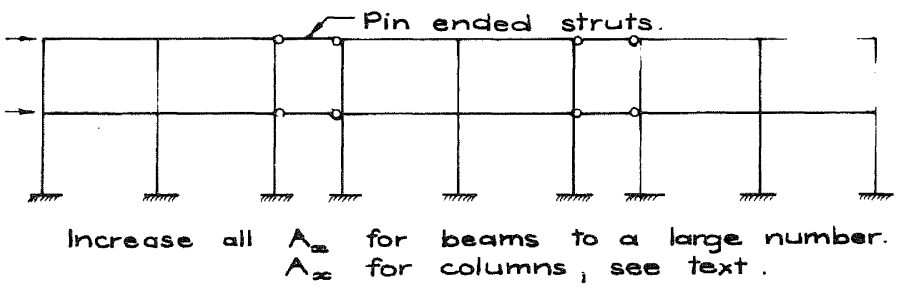

FIGURE 2: COMPUTER MODEL FOR PLANE FRAME ANALYSIS

Plan.

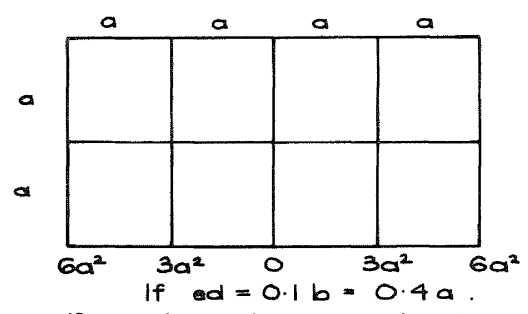

Percentage increase in shear in end bay

$\frac{0.4 a}{a} \times \frac{3}{15} \times \frac{6 a^{2}}{28 a^{2}}=17 \%$

FIGURE 3: TORSION CASE FOR EQUAL BAYS

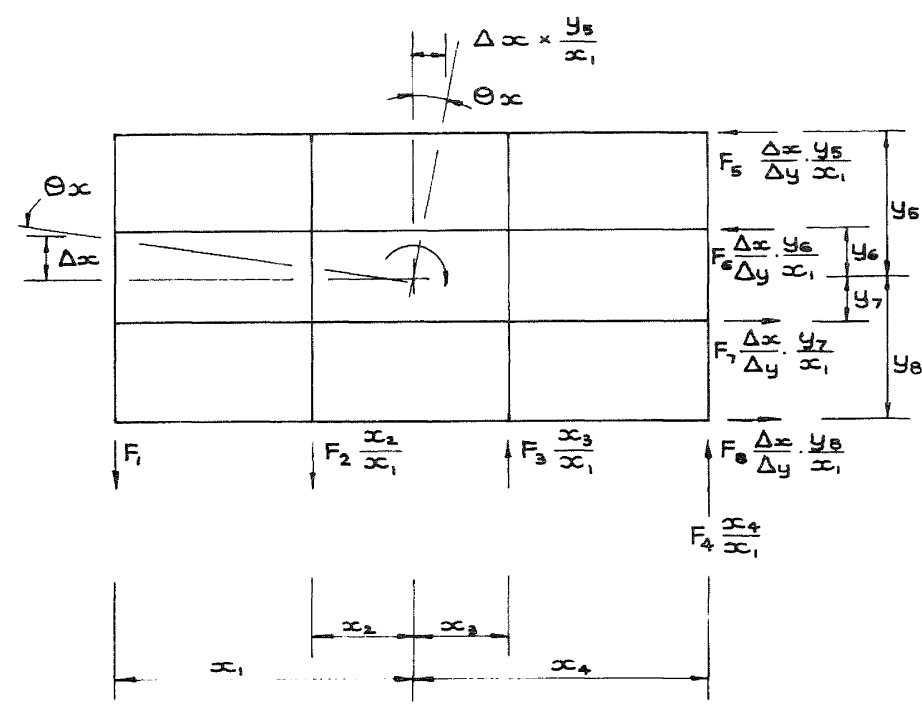

FIGURE 5: SCALING OF UNIAXIAL LOADING TO GENERATE TORSIONAL LOAD CASE
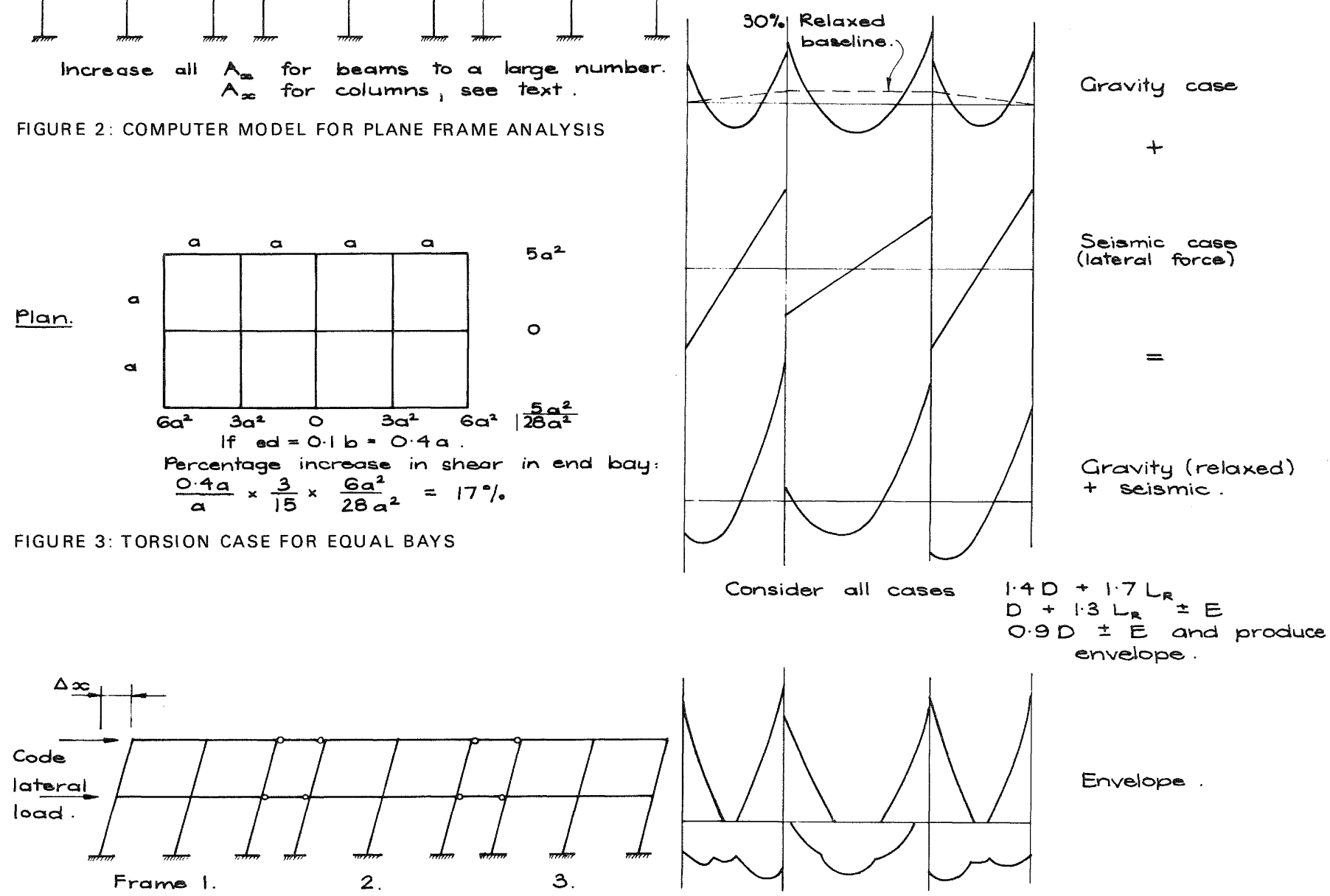

Envelope 
으.
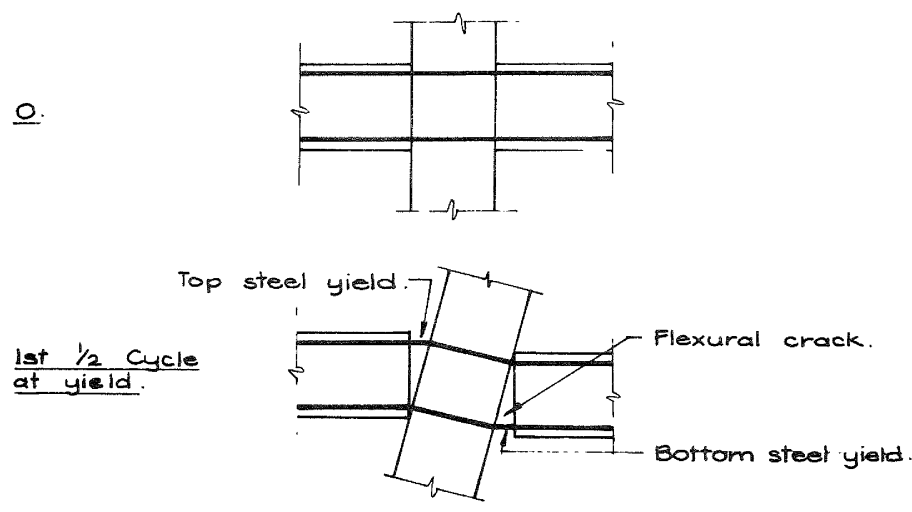

2nd $1 / 2$ cycle

at yield.

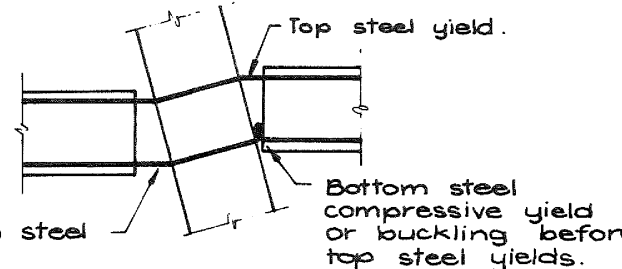

3rd $1 / 2$ cycle

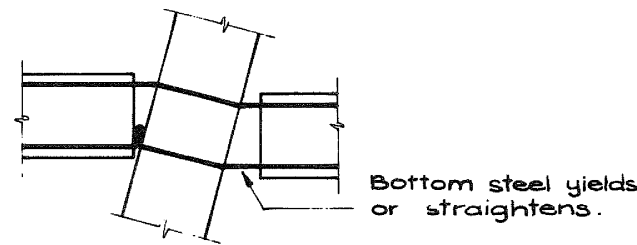

FIGURE 6a: YIELDING AND BUCK LING OF BEAM STEEL, AT COLUMN FACE UNDER LARGE CYCLIC LOADING, WHEN TOP STEEL GREATER THAN BOTTOM STEEL

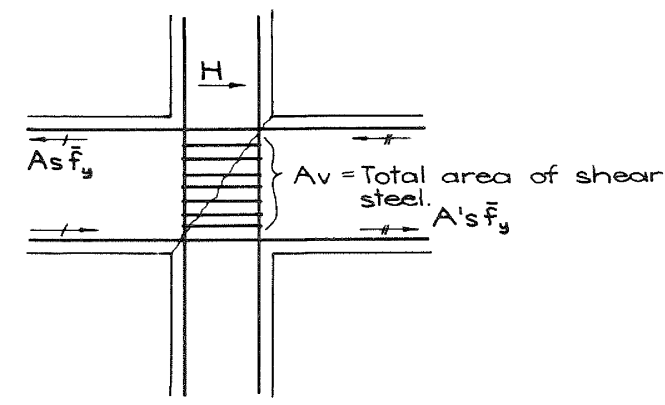

$$
A v=\frac{v_{j}}{\phi f_{y}}=\frac{A_{s} \bar{f}_{y}+A^{\prime} s \bar{f}_{y}-H}{\phi f_{y}}
$$

FIGURE 7: JOINT SHEAR DESIGN FOR UNIAXIAL CASE

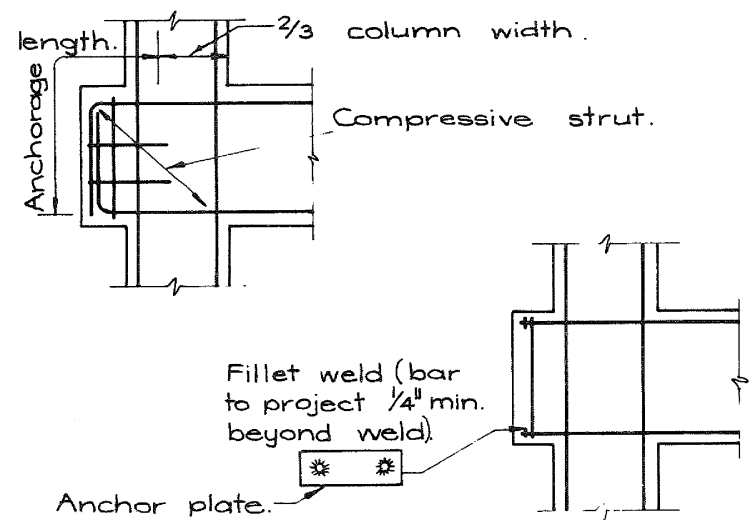

FIGURE $8 a$ \& 8 b: ANCHORAGE OF BEAM STEEL IN BEAM STUBS
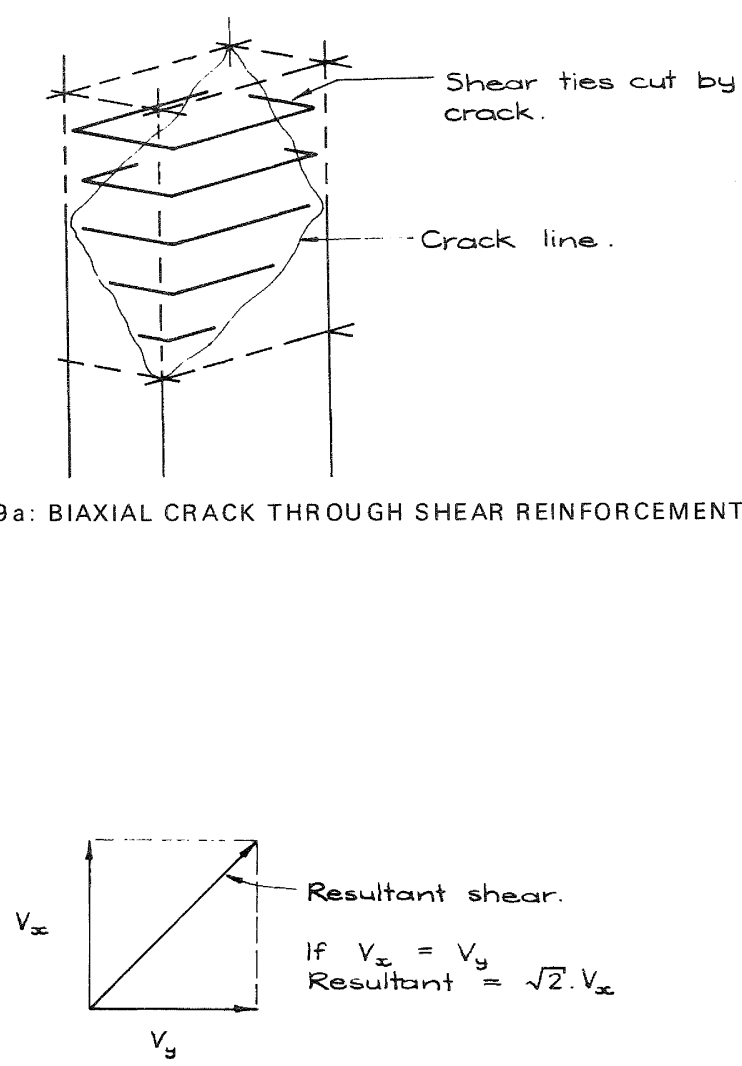

FIGURE 9b: SUMMATION OF BIAXIAL SHEAR

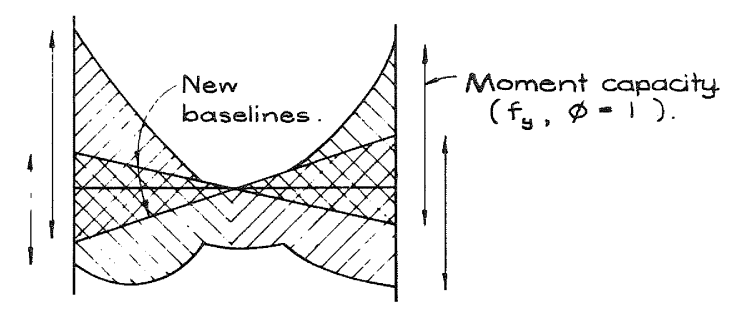

FIGURE 10: MOMENT ENVELOPES AT CAPACITY

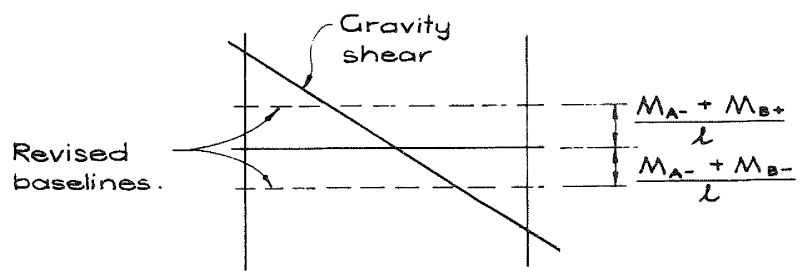

FIGURE 11: SHEAR ENVELOPES AT CAPACITY 


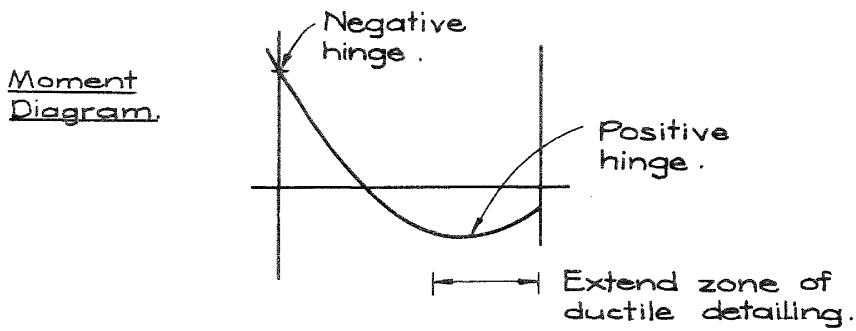

FIGURE 12: POSSIBLE INCREASE IN BEAM HINGE ZONE

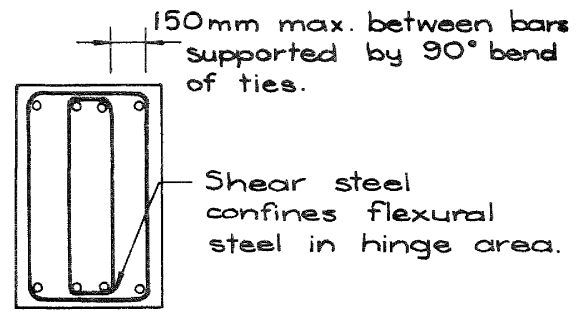

FIGURE 13: CONFINEMENT OF BEAM FLEXURAL STEEL

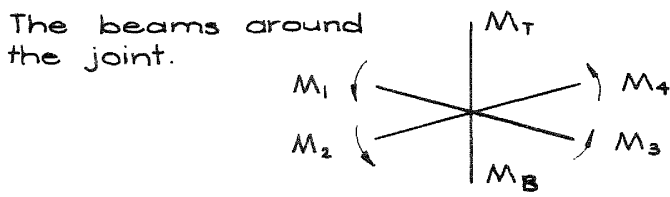

FIGURE 14: CAPACITY MOMENTS AT BEAM COLUMN JOINT

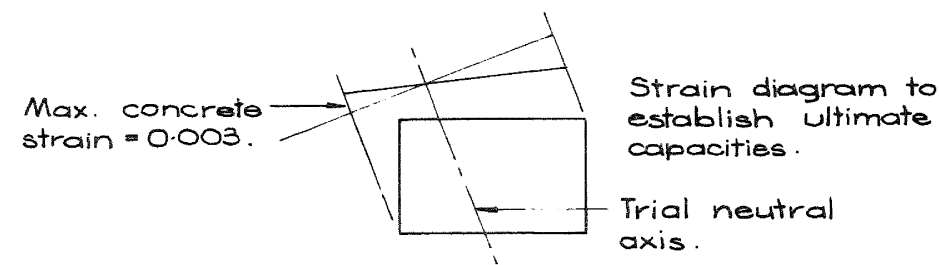

FIGURE 15: ULTIMATE STRAIN DIAGRAM FOR COLUMNS

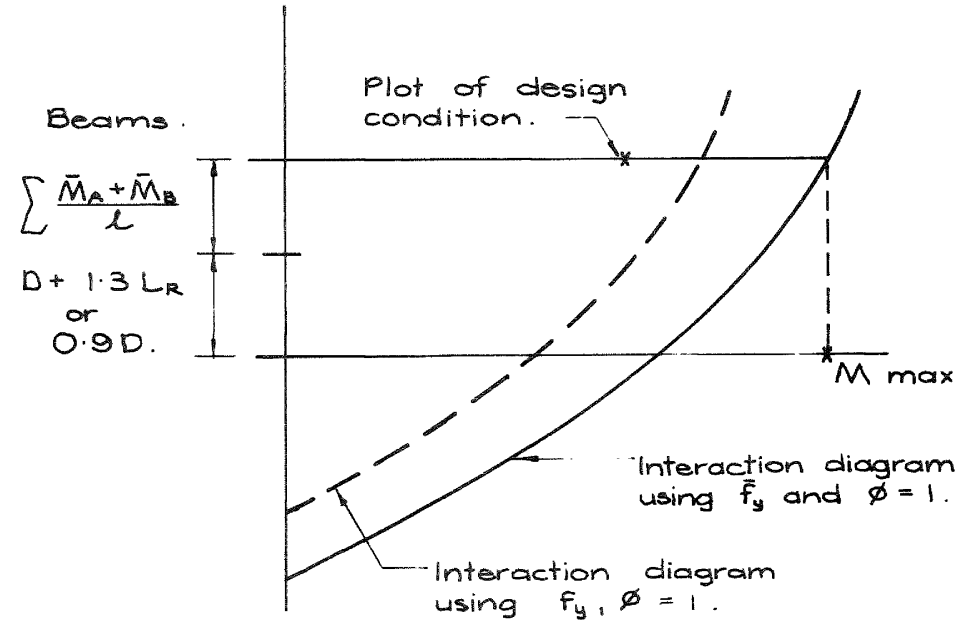

FIGURE 16: COLUMN INTERACTION DIAGRAMS

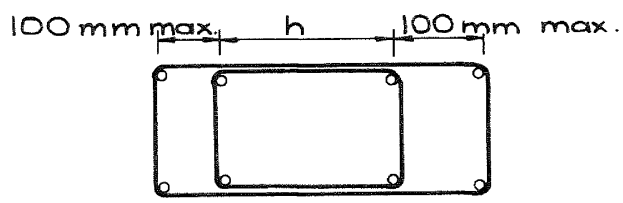

FIGURE 18: VARIATION IN TIE ARRANGEMENTS

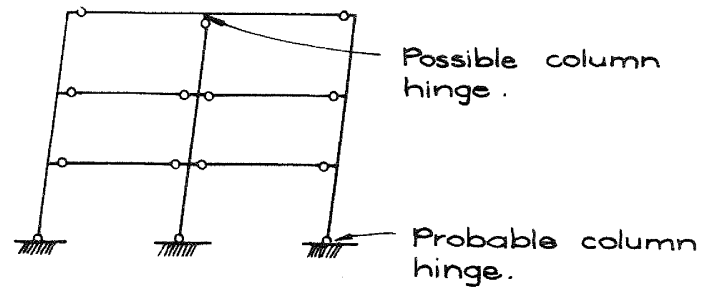

FIGURE 19: CAPACITY HINGES IN COLUMNS

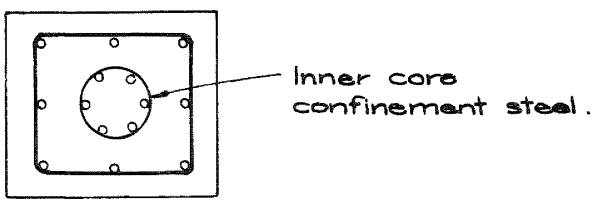

FIGURE 20: PROVISION FOR REPAIR OF COLUMN HINGES 